Journal Sosial Science and Teknology for Community Service (JSSTCS)

Vol. 1, No. 2, September 2020, page-page. 10 16

P-ISSN: 2723-2026

E-ISSN: 2723-455x

DOI: -

available online at: https://ejurnal.teknokrat.ac.id/index.php/teknoabdimas

\title{
PEMBELAJARAN TRADISIONAL MENUJU MILENIAL : PENGEMBANGAN APLIKASI BERBASIS WEB SEBAGAI PENUNJANG PEMBELAJARAN E-LEARNING PADA MAN 1 PESAWARAN
}

\author{
Styawati $^{1}$, Fenty Ariany ${ }^{2}$, Debby Alita ${ }^{3}$, Erliyan Redy Susanto ${ }^{4}$ \\ ${ }^{1,2,3,4}$ Universitas Teknokrat Indonesia
}

Email : styawati@teknokrat.ac.id ${ }^{1}$, fentyariani @teknokrat.ac.id ${ }^{2}$, debbyalita@teknokrat.ac.id ${ }^{3}{ }_{2}$ erliyanredysusanto@teknokrat.ac.id ${ }^{4}$

\begin{abstract}
Received: (date month year)
Accepted: (date month year)

Abstract

The teaching and learning process is very important in any situation. MAN 1 Pesawaran is one of the final level high schools. The learning process at MAN 1 Pesawaran during the Covid pandemic situation was using WhatsApp. The use of these applications in the teaching and learning process has many obstacles, including that students cannot see the value directly after they work on the exam questions. Apart from that, the teacher also cannot see the recap of student attendance and the recap of students who have participated in the lesson. Based on these problems, an E-Learning system was built using the PHP programming language, the Moodle 3.9 framework, the MYSQL database, and the Moove theme. This system has been tested with 6 respondents using the Blackbox Testing technique which shows the system being built is in accordance with user needs.
\end{abstract}

Published : (date month year )

Keywords: E-Learning, PHP, MYSQL,Moodle

\begin{abstract}
Abstrak
Proses belajar mengajar sangat penting dilakukan dalam situasi apapun. MAN 1 Pesawaran adalah salah satu sekolah menengah tingkat akhir. Proses pembelajaran di MAN 1 Pesawaran saat situasi pandemi covid menggunakan whatsapp. Penggunaan aplikasi tersebut dalam proses belajar mengajar memiliki banyak kendala, diantaranya yaitu siswa tidak dapat melihat secara langsung nilai setelah mereka mengerjakan soal ujian. Selain itu dari pihak guru juga tidak dapat melihat rekap kehadiran siswa dan rekap siswa yang telah mengikuti pembelajaran. Berdasarkan pada permasalahan tersebut, maka dibangun sistem E-Learning menggunakan bahasa pemrograman PHP, framework moodle 3.9, database MYSQL, dan theme Moove. Sistem ini telah diuji dengan 6 responden dengan menggunakan teknik pengujian Blackbox Testing yang menunjukan sistem yang dibangun telah sesuai dengan kebutuhan pengguna.
\end{abstract}

Kata Kunci: E-Learning, PHP, MYSQL,Moodle

To cite this article:

Authors. (Year). Title of the article. Journal of Technology and Social for Community Service (JTSCS), Vol(1), Page-Page.

\section{PENDAHULUAN}

Seiring dengan perkembangan zaman yang terus berkembang, terjadi perubahan pada kebutuhan manusia. Hal ini turut mengubah perkembangan sistem pendidikan yang ada di dunia dan di Indonesia. Institusi pendidikan tidak terlepas dari sistem pengolahan data, hal ini dikarenakan sistem tersebut terdiri dari sub-sub yang saling berkaitan untuk mengolah data yang berkaitan dengan masalah dan membantu organisasi dalam pengambilan keputusan [1]. Sistem pengolahan data secara online mempermudah pengguna dalam mengakses data dibandingkan dengan sistem offline [2], [3], [4] maka dari itu sistem pengolahan data sangat dibutuhkan 
pada sistem pendidikan. Sistem pendidikan adalah strategi atau metode yang digunakan dalam proses belajar mengajar untuk mencapai tujuan agar peserta didik dapat secara aktif mengembangkan potensi yang ada di dalam dirinya dan dengan menggunakan sistem pendidikan yang tepat dapat meningkatkan minat belajar siswa sehingga akan tercipta suasana pembelajaran yang menyenangkan antara guru dan siswa [5].

Pendidikan adalah salah satu faktor terpenting dalam usaha pembangunan yang dilakukan oleh sebuah Negara. Karena menurut [6] pendidikan merupakan upaya pengembangan potensi manusiawi dari para peserta didik, baik berupa fisik, cipta maupun karsa agar potensi tersebut menjadi nyata dan dapat berfungsi bagi perjalan kehidupan.

Perkembangan pendidikan di dunia tidak lepas dari adanya perkembangan dari revolusi industri yang terjadi pada dunia ini, karena secara tidak langsung perubahan tatanan pada ekonomi turut merubah tatanan pendidikan di suatu negara. Saat ini kita sedang menghadapi revolusi industri keempat yang dikenal dengan revolusi industri 4.0. Revolusi ini merupakan era inovasi disruptif, dimana teknologi pada era ini berkembang sangat pesat. Era digital ini bukan hanya berdampak pada bidang industri saja akan tetapi berdampak ke segala aspek kehidupan manusia tanpa kecuali dunia pendidikan. Menghadapi tantangan yang besar era revolusi industri 4.0, maka pendidikan dituntut untuk berubah mengikuti era revolusi ini, termasuk pendidikan pada jenjang menengah atas. Era pendidikan yang dipengaruhi oleh revolusi industri 4.0 disebut Pendidikan 4.0 yang bercirikan pemanfaatan teknologi digital dalam proses pembelajaran dikenal dengan sistem siber (cyber system) dan mampu membuat proses pembelajaran berlangsung secara kontinu tanpa batas ruang dan tanpa batas waktu.

Inovasi pendidikan dapat dikatakan sebagai sebuah usaha untuk mengadakan suatu perubahan dengan tujuan untuk memperoleh hal yang lebih baik dalam bidang pendidikan [7]. Salah satu bentuk inovasi pendidikan adalah dengan penerapan sistem belajar online atau sering disebut dengan e-Learning. E-learning biasanya menggunakan teknologi jaringan informasi dan komunikasi pada proses pembelajaran. Huruf "E" pada Elearning berasal dari kata electronic, e-learning dapat diartikan semua kegiatan yang berhubungan dengan pembelajaran secara individu atau kelompok, online atau offline, dan synchronous atau asynchronous dengan menggunakan komputer ataupun peralatan elektronik lainya [8]. Saat ini konsep E-Learning sudah banyak diterima oleh masyarakat dunia, terbukti dengan banyaknya implementasi E-Learning di perguruan tinggi dan sekolah. Namun masih banyak juga sekolah yang belum menerapkan sistem E-Learning terutama di wilayah kabupaten. Salah satunya adalah MAN (Madrasah Aliyah Negeri) 1 Pesawaran.

MAN (Madrasah Aliyah Negeri) 1 Pesawaran adalah sekolah yang setara dengan Sekolah Menengah Atas (SMA). Sekolah ini beralamat di jalan Kertasana No. 1 Desa Gunung Sugih Kedondong Pesawaran. Sejak pandemi Covid 19 melanda Indonesia, pemerintah menerapkan social distancing, dimana sekolah memberlakukan kegiatan belajar mengajar dari rumah dengan menggunakan media aplikasi whatsapp. Sekolah ini memiliki infrastruktur yang memadai, seperti laboratorium komputer dan koneksi internet. Hal ini memungkinkan MAN 1 Pesawaran dapat mengembangkan sistem E-Learning sehingga pemanfaatan komputer dan internet menjadi lebih optimal. Sistem E-Learning memberikan kemudahan kepada admin, guru maupun siswa serta sistem ini dapat diakses kapanpun dan dimanapun [5].

\section{METODE PELAKSANAAN Tempat dan Waktu}

Sistem e-Learning ini diterapkan di MAN 1 Pesawaran yang terletak di Jalan Kertasana No. 1, Gunung Sugih, Kecamatan Kedondong, Kabupaten Pesawaran. Kegiatan ini dimulai dari bulan Juli 2020. Sistem ini diimplementasikan pada tanggal 1 September 2020.

\section{Khalayak Sasaran}

Sasaran dalam kegiatan ini yaitu admin, guru dan siswa di MAN 1 Pesawaran. Jumlah kelas yang ada di MAN 1 Pesawaran yaitu sebanyak 21 kelas yang terdiri dari dua jurusan yaitu jurusan Ilmu Pengetahuan Alam (IPA) dan Ilmu Pengetahuan Sosial (IPS).

\section{Teknik Pengumpulan Data}

Pengumpulan data dilakukan untuk memperoleh informasi yang dibutuhkan untuk mencapai tujuan. Dalam kegiatan ini, penulis menggunakan beberapa cara dalam mengumpulkan data, yaitu sebagai berikut :

1. Tinjauan Pustaka 
Metode pengumpulan data atau informasi yang dilakukan dengan cara mempelajari berbagai jurnal penelitian, sumber bacaan serta buku-buku referensi yang berkaitan atau berhubungan dengan topik usulan penelitian yang sedang diteliti.

\section{Wawancara}

Metode wawancara yaitu metode pengumpulan data yang dilakukan dengan cara menanyakan langsung kepada pihak yang berkaitan dengan kegiatan belajar mengajar untuk memperoleh informasi. Wawancara dalam penelitian ini dilakukan dengan kepala sekolah MAN 1 Pesawaran.

\section{Metode Pengabdian}

Pada program PKM ini menggunakan metode pendekatan kualitatif berupa pendekatan institusional dan pendekatan partisipatif. Pendekatan institusional akan dilakukan melalui komunikasi dua arah secara langsung maupun tidak langsung perihal apa saja kebutuhan yang sangat diperlukan oleh MAN 1 Pesawaran dan juga perihal masalah-masalah yang sering dihadapi oleh guru pada saat pembelajaran secara konvensional. Selain itu, melalui pendekatan institusional, tim pelaksana Pengabdian Kepada Masyarakat (PKM) akan mendiskusikan solusi-solusi dan tahapan pelaksanaan pengabdian. Pendekatan partisipatif juga akan digunakan dengan cara melibatkan seluruh guru dan peserta didik agar tercapainya kebutuhan sekolah dengan menggunakan proses diskusi dan sosialisasi/pelatihan.

\section{HASIL DAN PEMBAHASAN}

Pengabdian Kepada Masyarakat yang dilakukan yaitu mengimplementasikan sistem pembelajaran berbasis online yang sering disebut E-Learning. E-Leraning pada MAN 1 Pesawaran dapat diakses melalui URL http://manlpesawaran.rumahdaring.com. Sistem E-Learning ini dibangun menggunakan bahasa pemrograman PHP, framework moodle 3.9, database MYSQL, dan theme Moove. PHP merupakan salah satu bahasa pemograman berbasis web dimana sistem yang diterapkan adalah pada sisi server side [9]. Moodle adalah paket perangkat lunak yang diproduksi untuk kegiatan belajar berbasis internet dan situs yang menggunakan prinsip social constructionist pedagogy. Moodle merupakan salah satu LMS open source yang dapat dengan mudah dipakai untuk mengembangkan system E-Learning. Dengan Moodle E-Learning dapat dimodifikasi sesuai kebutuhan. Salah satu keuntungan bagi pendidik membuat pembelajaran online berbasis LMS adalah kemudahan [10]. Moodle berfungsi sebagai alat bantu yang efektif dalam menyediakan fasilitas pembelajaran karena dilengkapi dengan fitur-fitur penting penunjang pembelajaran seperti tugas, quiz, komunikasi, kolaborasi, serta fitur utama yang dapat meng-upload berbagai format materi pembelajan [11]. MySQL adalah program database server yang mampu menerima dan mengirimkan data dengan sangat cepat, multi user serta menggunakan peritah standar SQL (Structured Query Language) dan baik digunakan sebagai client maupun server [12]. Gambaran sistem ini dapat dilihat pada use case diagram Gambar 1.

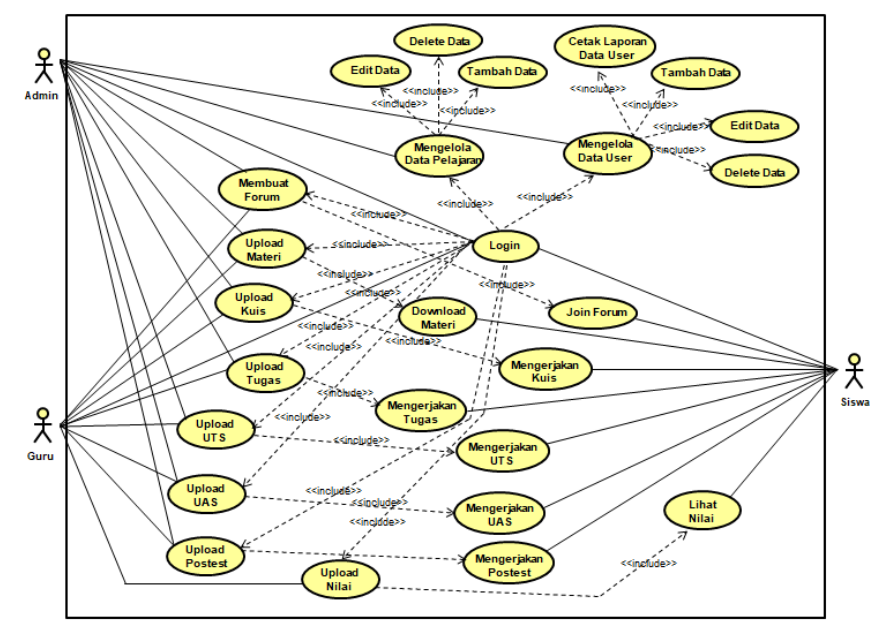

Gambar 1. Use Case Diagram Sistem E-Learning

Sistem E-Learning yang dibangun pada MAN 1 Pesawaran memiliki tampilan sebagai berikut 
1. Tampilan Halaman Login

Halaman login berfungsi untuk pengguna (Admin, Siswa dan Guru) dapat masuk kedalam sistem ELearning dengan cara menginputkan username dan password.

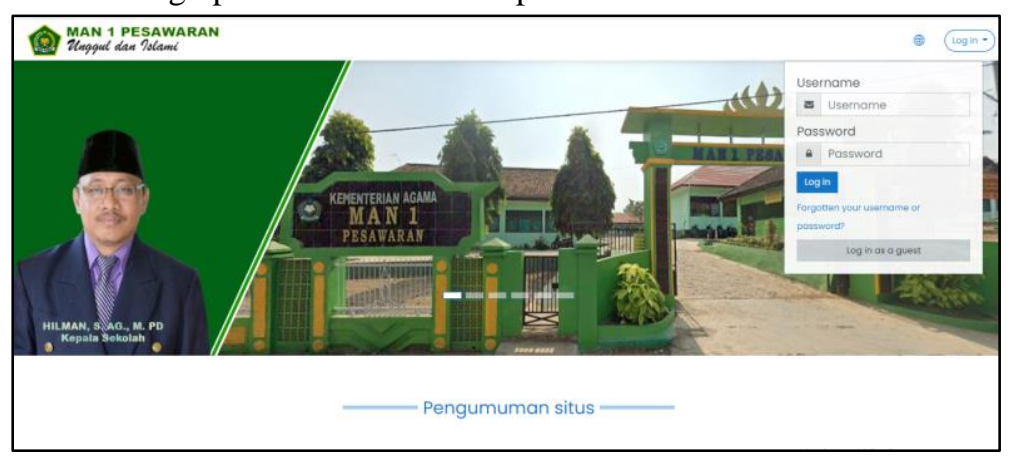

2. Halaman Mengelola Pengguna

Gambar 2. Tampilan Halaman Login

Halaman Mengelola Pengguna berfungsi untuk membuat, mengganti dan menghapus data pengguna.

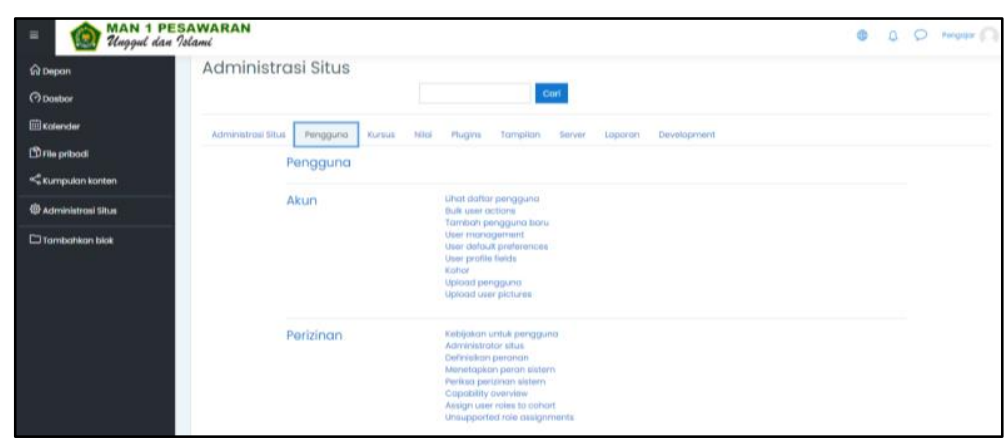

Gambar 3. Tampilan Halaman Mengelola Pengguna

3. Halaman Mengelola Mata Pelajaran

Halaman Mengelola Mata Pelajaran berfungsi untuk menambah, mengganti dan menghapus data mata pelajaran.

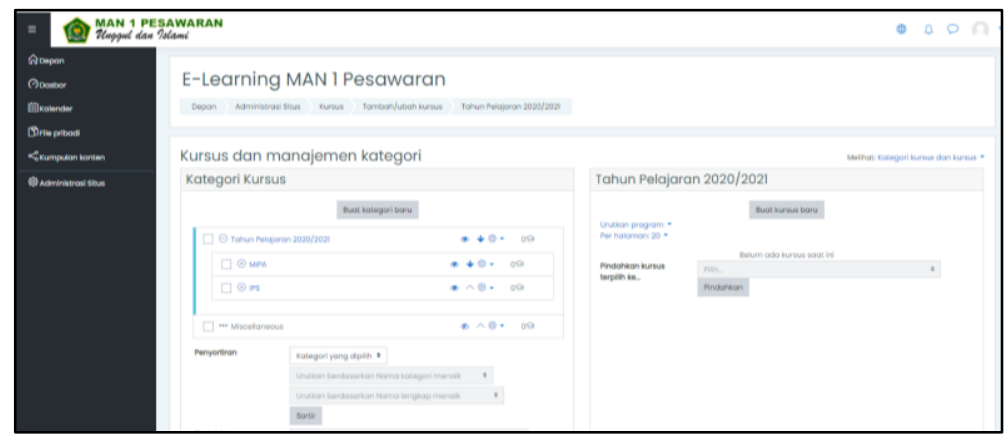

Gambar 4. Tampilan Halaman Mengelola Mata Pelajaran

4. Halaman Tambah Mata Pelajaran

Halaman Tambah Mata Pelajaran berfungsi untuk menambah mata pelajaran 


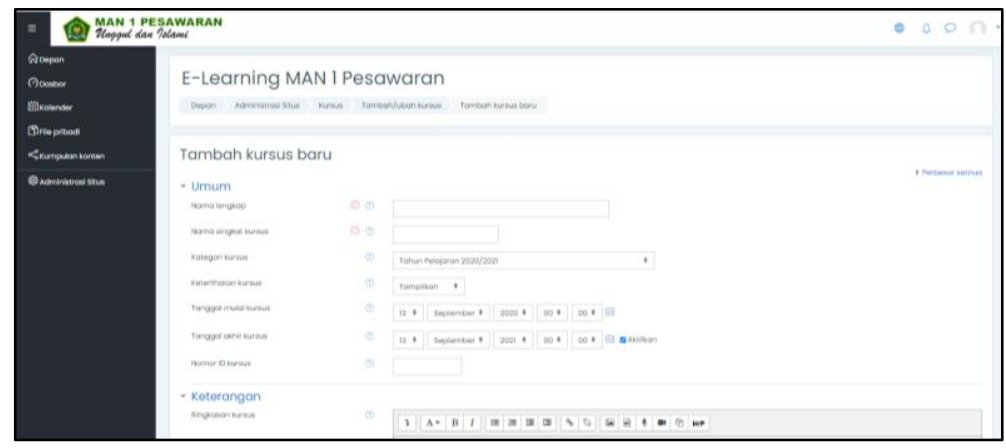

Gambar 5. Tampilan Halaman Tambah Mata Pelajaran

5. Halaman Membuat Forum

Halaman Membuat Forum berfungsi untuk berdiskusi antara guru dengan siswa ataupun siswa dengan siswa terkait materi tertentu yang telah diberikan oleh guru.

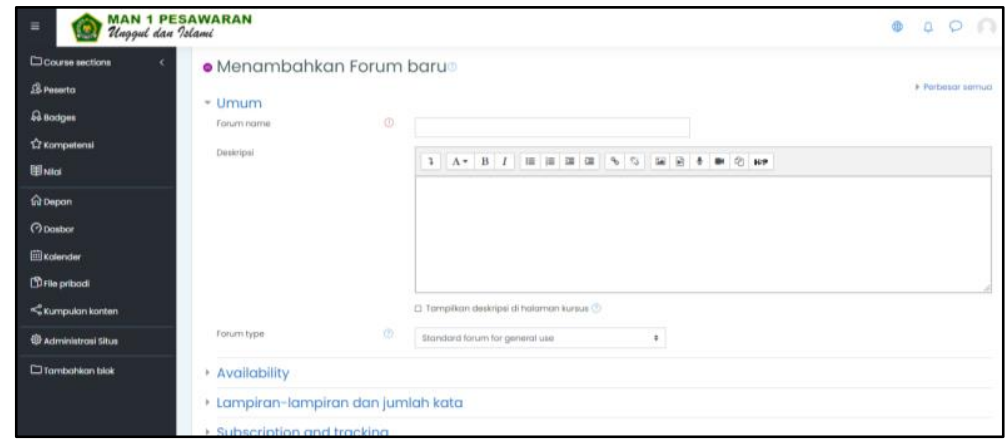

Gambar 6. Tampilan Halaman Membuat Forum

6. Halaman Upload Materi

Halaman Upload Materi berfungsi untuk guru mengunggah materi yang akan disampaikan kepada siswa-siswi MAN 1 Pesawaran.

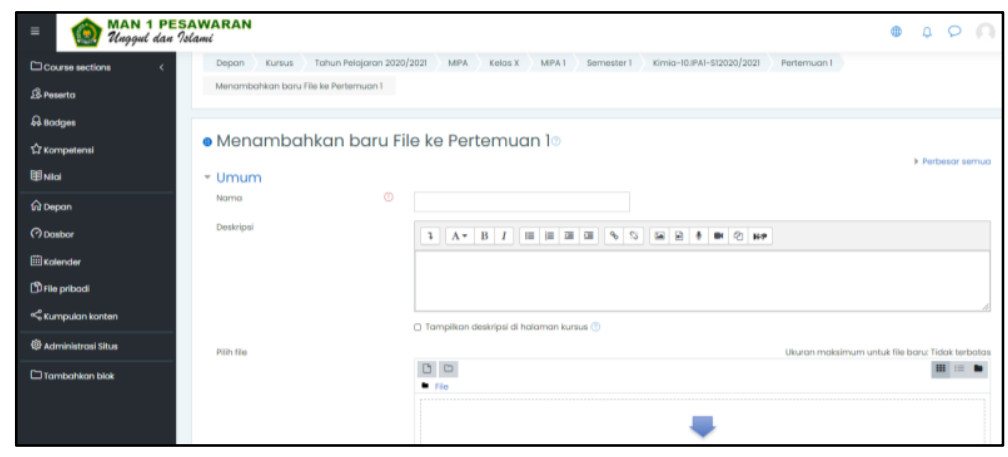

Gambar 7. Tampilan Halaman Upload Materi

7. Halaman Upload Kuis

Halaman Upload Kuis berfungsi mengunggah kuis yang akan diberikan kepada siswa-siswi MAN 1 Pesawaran. 


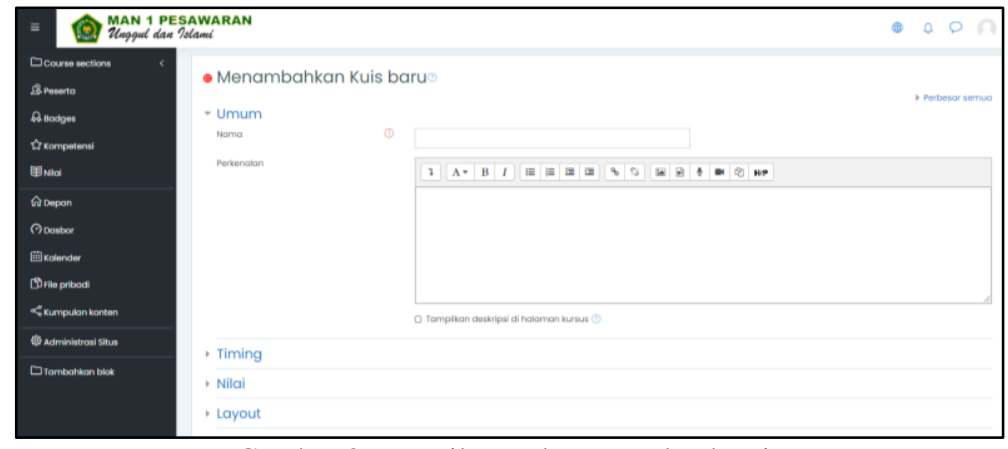

8. Halaman Upload Tugas

Gambar 8. Tampilan Halaman Upload Kuis

Halaman Upload Tugas berfungsi untuk berfungsi mengunggah tugas yang akan diberikan kepada siswa-siswi MAN 1 Pesawaran

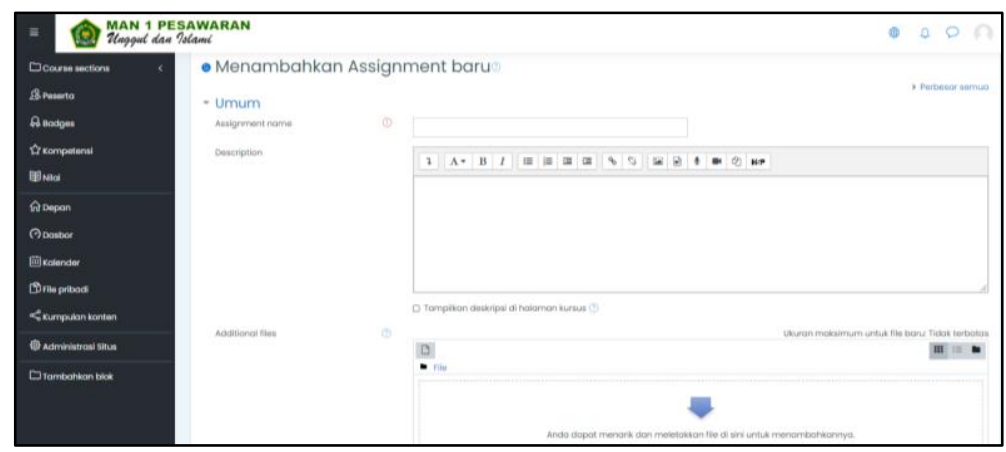

9. Download Nilai

Gambar 9. Tampilan Halaman Upload Tugas

Halaman Download Nilai berfungsi untuk guru mengunduh nilai siswa yang telah mengerjakan postest, kuis, UTS dan UAS dengan kategori soal pilihan ganda.

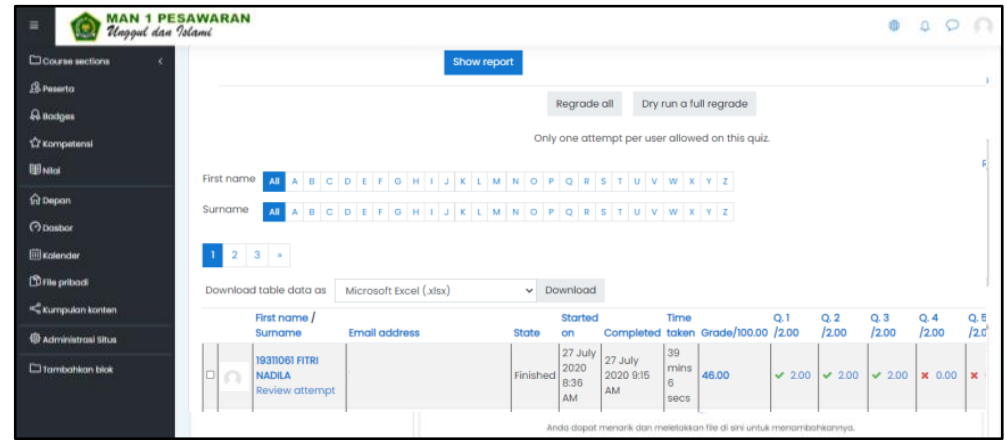

Gambar 9. Tampilan Halaman Download Nilai

\section{KESIMPULAN}

Berdasarkan pada PKM yang telah dilaksanakan dapat disimpulkan bahwa Sistem E-Learning sangat dibutuhkan oleh MAN 1 Pesawaran saat situasi covid maupun situasi normal. Saat situasi covid siswa tetap dapat belajar dari rumah tanpa harus berkerumun dengan siswa lain. Saat situasi normal sistem ini dapat digunakan oleh para Guru untuk menyampaikan materi meskipun para Guru tersebut tidak berada di sekolah atau sedang tugas luar, sedangkan untuk para Siswa tetap dapat mengakses materi meskipun tidak melalui pembelajaran secara tatap muka. Sistem ini telah diuji dengan 6 responden dengan menggunakan teknik pengujian blackbox testing yang menunjukan sistem yang dibangun telah sesuai dengan kebutuhan pengguna. 


\section{UCAPAN TERIMA KASIH}

Ucapan terima kasih kami sampaikan kepada Universitas Teknokrat Indonesia yang telah memberikan hibah Pengabdian Kepada Masyarakat (PKM) tahun pelaksanaan 2020. Kami ucapkan terima kasih juga kepada Kepala Sekolah MAN 1 Pesawaran yang telah memberikan kesempatan kepada kami untuk melaksanakan PKM dengan mengimplementasikan sistem E-Learning ini.

\section{REFERENSI/DAFTAR PUSTAKA}

[1] A. E. Kumala, R. I. Borman, and P. Prasetyawan, "Sistem Informasi Monitoring Perkembangan Sapi Di Lokasi Uji Performance (Studi Kasus : Dinas Peternakan Dan Kesehatan Hewan Provinsi Lampung), J J. Tekno Kompak, vol. 12, no. 1, p. 5, 2018, doi: 10.33365/jtk.v12i1.52.

[2] I. Ahmad et al., "Penerapan Algoritma Rekomendasi Pada Aplikasi Rumah Madu Untuk Perhitungan Akuntansi Sederhana Dan Marketing Digital,” IIB Darmajaya, pp. 38-45, 2019.

[3] T. D. Rosmalasari, M. A. Lestari, F. Dewantoro, and E. Russel, "Pengembangan E-Marketing Sebagai Sistem Informasi," vol. 1, no. 1, pp. 27-32, 2020.

[4] S. D. Riskiono, F. Hamidy, and T. Ulfia, "Sistem Informasi Manajemen Dana Donatur Berbasis Web Pada Panti Asuhan Yatim Madani,” J. Soc. Sci. Technol. Community Serv., vol. 1, no. 1, pp. 21-26, 2020.

[5] A. Munandar, H. Sulistiani, Q. J. Adrian, and A. Irawan, "Penerapan Sistem Informasi Pembelajaran Online Di Smk Al-Huda Lampung Selatan,” J. Technol. Soc. Community Serv., vol. 1, no. 1, pp. 7-14, 2020.

[6] A. Salahudin, Filsafat Pendidikan. Bandung: Pustaka Setia, 2011.

[7] M. Kristiawan and Et.al, Inovasi pendidikan, no. Juni. 2018.

[8] Z. Zyainuri and E. Marpanaji, "Penerapan e-learning moodle untuk pembelajran siswa yang melaksanakan prakerin," J. Pendidik. Vokasi, vol. 2, no. 3, pp. 410-426, 2013, doi: 10.21831/jpv.v2i3.1046.

[9] K. S. Haryana, "Pengembangan Perangkat Lunak Dengan Menggunakan Php," J. Comput. Bisnis, vol. 2, no. 1, pp. 14-21, 2008, [Online]. Available: http://jurnal.stmik-mi.ac.id/index.php/jcb/article/view/74.

[10] L. Herayanti, M. Fuaddunnazmi, and H. Habibi, "Pengembangan Perangkat Pembelajaran Fisika Berbasis Moodle,” J. Pendidik. Fis. dan Teknol., vol. 3, no. 2, p. 197, 2017, doi: 10.29303/jpft.v3i2.412.

[11] M. R. Safitri, R. Budiharti, and E. Y. Ekawati, "Pengembangan Media Pembelajaran IPA Terpadu Interaktif Dalam Bentuk Moodle Untuk Siswa SMP Pada Tema Hujan Asam,” J. Pendidik. Fis., vol. 2 , pp. 1-5, 2014.

[12] E. Usada, Y. Yuniarsyah, and N. Rifani, "Rancang Bangun Sistem Informasi Jadwal Perkuliahan Berbasis Jquery Mobile Dengan Menggunakan PHP Dan MySQL," J. INFOTEL - Inform. Telekomun. Elektron., vol. 4, no. 2, p. 40, 2012, doi: 10.20895/infotel.v4i2.107. 